\title{
Study of Ofner's Method for the Determination of Invert Sugar
}

\author{
By Emma J. McDonald and Anne L. Turcotte
}

\begin{abstract}
In a previous investigation Jackson and McDonald studied Ofner's method for the determination of invert sugar in sucrose. They modified the procedure and were thus able to increase the reproducibility of results when determining from 5 to $25 \mathrm{mg}$ of invert sugar in the presence of sucrose. This method has now been applied to pure invert sugar and to sugar samples containing $5 \mathrm{mg}$ or less of invert sugar in $10 \mathrm{~g}$ of sucrose. It has proved to be a suitable method for the analysis of high-grade refined sugars as well as for the determination of $25 \mathrm{mg}$ or less of invert sugar alone. A table is given for the conversion of milliliters of iodine consumed to milligrams of invert sugar present.
\end{abstract}

\section{Introduction}

It has long been recognized that copper solutions of low alkalinity are better suited for the analysis of small amounts of invert sugar in the presence of sucrose than are those of higher alkalinity. The method devised by Ofner [1] ${ }^{1}$ for the determination of invert sugar in refined sugars has been subjected to critical study by Jackson and McDonald [2]. These authors recommended the use of the Ofner method with some modifications. These included the substitution of an ordinary asbestos gauze plate for the metal gauze, thus insuring more uniform heating and the elimination of the "flame spot." The precision of the method was greatly increased by acidifying with acetic acid before the addition of iodine and subsequent addition of hydrochloric acid. Thus, the rapid oxidation of cuprous chloride in acid solution was eliminated.

Jackson and McDonald confined their experiments to sugar samples containing from 5 to 25 $\mathrm{mg}$ of invert sugar, which amounts to 0.05 to 0.25 percent when a $10-\mathrm{g}$ sample is used. In the present investigation the precision of the method

1 Figures in brackets indicate the literature references at the end of this paper. was determined with invert sugar alone, and with sugar samples containing less than 0.05 percent of invert sugar. The results further confirm the validity of the modified Ofner method for the analysis of refined sugars.

Experience has shown that invert sugar can be determined more accurately alone than when in the presence of sucrose. Therefore, it seemed advisable to base the results on the invert-sugar values and to apply a correction for the increased reduction due to the action of the sucrose.

\section{Contents}

I. Introduction

II. Analytical procedure _._.

1. Method . . . . . . . 430

(a) Reagents_................. 430

(b) Procedure

III. Reducing power of invert sugar _........... 431

IV. Effect of sucrose on the reducing power of invert sugar _...

V. Summary and conclusions _._. _. _ _ _ _ _ 434

VI. References. . . . . . . 


\section{Analytical Procedure}

Invert sugar used in these experiments was prepared by weighing equal quantities of levulose and dextrose and by the hydrolysis of pure sucrose. Identical analytical results were obtained from invert sugar prepared by the two procedures. The sucrose and dextrose used were National Bureau of Standards Standard Samples 17 and 41, respectively; the levulose was purified by repeated crystallization from aqueous alcohol solution. Iodine of a normality of 0.0323 was used except when $5 \mathrm{mg}$ or less of invert sugar was determined, in which case $0.00323 \mathrm{~N}$ iodine was employed. All results were expressed in terms of the $0.0323 \mathrm{~N}$ solution. The concentration of the iodine solution was determined by volumetric titration against thiosulfate of the same normality. The thiosulfate solution was repeatedly standardized [3, 4] against pure copper or a copper sulfate solution in which the copper had been determined electrolytically.

\section{Method}

\section{(a) Reagents}

Copper solution.-Dissolve $5.0 \mathrm{~g}$ of $\mathrm{CuSO}_{4} .5 \mathrm{H}_{2} \mathrm{O}$, $10.0 \mathrm{~g}$ of anhydrous $\mathrm{Na}_{2} \mathrm{CO}_{3}, 300 \mathrm{~g}$ of pulverized Rochelle salt, and $50 \mathrm{~g}$ of $\mathrm{Na}_{2} \mathrm{HPO}_{4} \cdot 12 \mathrm{H}_{2} \mathrm{O}$, or $19.8 \mathrm{~g}$ of anhydrous salt in about $900 \mathrm{ml}$ of water, warming finally if necessary. When these reagents are completely dissolved, it is advisable to continue heating for 2 hours on the water bath to destroy mold spores. Cool, and adjust the volume to 1 liter. Treat with active carbon or kieselguhr and filter, or filter directly through sintered glass having fine pores. Preserve in a dark place.

Sodium thiosulfate solution.-Dissolve $4.00 \mathrm{~g}$ of crystals and dilute to a volume of $500 \mathrm{ml}$ or, preferably, prepare a stock solution containing in 500 $\mathrm{ml}, 20.0 \mathrm{~g}$ of crystals and $1 \mathrm{ml}$ of $1 \mathrm{~N} \mathrm{NaOH}$ or $0.1 \mathrm{~g}$ of $\mathrm{Na}_{2} \mathrm{CO}_{3}$. Dilute $100 \mathrm{ml}$ of this stock solution to $500 \mathrm{ml}$ as required. Standardize by titration against pure copper solution.

Iodine solution.-Dissolve $2.05 \mathrm{~g}$ of pure iodine in about $10 \mathrm{~g}$ of iodate-free $\mathrm{KI}$ dissolved in a few milliliters of water. Dilute to a volume of exactly $500 \mathrm{ml}$ and preserve in a dark place. This solution is $0.03230 \mathrm{~N}$. It is repeatedly standardized against copper by means of the thiosulfate.

Starch solution.-Rub $2.5 \mathrm{~g}$ of soluble starch and about $10 \mathrm{mg}$ of $\mathrm{HgI}_{2}$ in a little water. Dissolve in about $500 \mathrm{ml}$ of boiling water.

\section{(b) Procedure}

Dissolve a 20 -g sample of the sugar in distilled water and dilute to $100 \mathrm{ml}$. Transfer $50 \mathrm{ml}$ of the solution containing not more than $20 \mathrm{mg}$ of invert sugar to a $300-\mathrm{ml}$ Erlenmeyer flask and add $50 \mathrm{ml}$ of the copper reagent. Mix well, add 50 to $100 \mathrm{mg}$ of pumice or talcum powder, cover with a glass bulb or inverted beaker, and heat to boiling on an absestos gauze plate during 4 to 5 minutes. Judge the initial time of boiling, not when bubbles arise from the bottom of the flask, but when they burst at the surface in considerable number. Continue the boiling for exactly 5 minutes. Cool without agitation by immersion in cold tap water. Add $1 \mathrm{ml}$ of glacial acetic acid. Add with continuous agitation an accurately measured volume of iodine, 5 to $30 \mathrm{ml}$, according to the amount of copper reduced, so that an excess is finally present. Pour down the wall of the flask from a graduated cylinder $15 \mathrm{ml}$ of $1 N \mathrm{HCl}$. Stopper the flask and allow the iodine to react for about 2 minutes, occasionally agitating the solution. Titrate the excess iodine with thiosulfate, with the addition of starch as the end point is approached. 


\section{Reducing Power of Invert Sugar}

Forty-five analyses were made in which quantities of invert sugar varying from 0.5 to $25 \mathrm{mg}$ were determined. The data were treated by the method of averages in order to obtain a mathematical relation between the iodine consumed and the invert sugar present. It was found than when not more than $5 \mathrm{mg}$ of invert sugar was present, the following linear relation existed:

$$
S=0.177+1.0124 I,
$$

where $S=$ milligrams of invert sugar, and $I=$ milliliters of $0.0323 \mathrm{~N}$ iodine consumed. Above this range the following quadratic equation was found to apply:

$$
S=0.817+0.855 I+0.005117 I^{2}
$$

Table 1 records a series of determinations of known quantities of invert sugar, in which the sugar is calculated from the iodine consumed by means of equation 1 or 2 .

Ofner found that $1 \mathrm{ml}$ of $0.0323 \mathrm{~N}$ iodine was equivalent to $1 \mathrm{mg}$ of invert sugar. The changes in the procedure, however, make the results more reproducible, and thus the analytical results warrant the more precise mathematical treatment. Table 2 correlates the iodine consumed and the invert sugar present. It is calculated by means of the above equations and is intended for practical application.

\begin{tabular}{|c|c|c|c|c|c|c|c|}
\hline \multirow[b]{2}{*}{$\begin{array}{c}0.0323 \\
N \\
\text { iodine }\end{array}$} & \multicolumn{3}{|c|}{ Invert sugar } & \multirow[b]{2}{*}{$\begin{array}{c}0.0323 \\
N \\
\text { iodine }\end{array}$} & \multicolumn{3}{|c|}{ Invert sugar } \\
\hline & $\begin{array}{c}\text { Pres- } \\
\text { ent }\end{array}$ & $\begin{array}{c}\text { Deter- } \\
\text { mined } \\
\text { from } I_{2} \\
\text { consumed } \\
\text { by means } \\
\text { of equa- } \\
\text { tion } 1 \text { or } 2\end{array}$ & $\begin{array}{l}\text { Differ- } \\
\text { ence }\end{array}$ & & $\begin{array}{c}\text { Pres- } \\
\text { ent }\end{array}$ & $\begin{array}{c}\text { Deter- } \\
\text { mined } \\
\text { from } I_{2} \\
\text { consumed } \\
\text { by means } \\
\text { of equa- } \\
\text { tion 1 or } 2\end{array}$ & $\begin{array}{c}\text { Differ- } \\
\text { ence }\end{array}$ \\
\hline$m l$ & $m g$ & $m g$ & $m g$ & $m l$ & $m g$ & $m g$ & $m g$ \\
\hline 0.33 & 0.5 & $=0.5$ & 0.0 & 19. 94 & 10.0 & 9.8 & -0.2 \\
\hline .51 & .7 & .7 & .0 & 12. 62 & 12.5 & 12.4 & -.1 \\
\hline .82 & 1.0 & 1.0 & .0 & 12. 71 & 12.5 & 12.5 & .0 \\
\hline .81 & 1.0 & 1.0 & .0 & 12. 72 & 12. 5 & 12.5 & .0 \\
\hline 1. 27 & 1.5 & 1.5 & .0 & 12. 59 & 12.5 & 12.4 & -.1 \\
\hline 1.75 & 2.0 & 2. 0 & .0 & 12. 55 & 12. 5 & 12.35 & -.15 \\
\hline 1. 76 & 2. 0 & 2. 0 & .0 & 15.14 & 15.0 & 14.9 & -.1 \\
\hline 1.76 & 2. 0 & 2. 0 & .0 & 15. 52 & 15.0 & 15.3 & +.3 \\
\hline 2. 21 & 2. 5 & 2.4 & -.1 & 15.00 & 15.0 & 14.8 & -.2 \\
\hline 2. 75 & 3. 0 & 3. 0 & .0 & 15. 29 & 15.0 & 15.1 & +.1 \\
\hline 2. 78 & 3. 0 & 3.0 & .0 & 17. 18 & 16.9 & 17.0 & +.1 \\
\hline 3. 01 & 3. 4 & 3.2 & -.2 & 17. 63 & 17. 5 & 17. 5 & .0 \\
\hline 3. 80 & 4. 0 & 3.9 & -.1 & 17.47 & 17. 5 & 17.3 & -.2 \\
\hline 3. 86 & 4. 0 & 4.1 & +.1 & 20.04 & 20.0 & 20.0 & .0 \\
\hline 4. 05 & 4. 4 & 4.3 & -.1 & 19.85 & 20.0 & 19.8 & -.2 \\
\hline 4.90 & 5.0 & 5.1 & +.1 & 20.11 & 20.0 & 20.1 & +.1 \\
\hline 4. 94 & 5.0 & 5.2 & +.2 & 22. 52 & 22.5 & 22.7 & +.2 \\
\hline 4. 93 & 5. 0 & b 52 & +.2 & 22.40 & 22.5 & 22.5 & .0 \\
\hline 7. 46 & 7. 5 & 7.5 & .0 & 22. 31 & 22.5 & 22.4 & -.1 \\
\hline 7.48 & 7. 5 & 7.5 & .0 & 24. 52 & 25.0 & 24.9 & -.1 \\
\hline 7.43 & 7.5 & 7.45 & -.05 & 24.85 & 25.0 & 25. 2 & +.2 \\
\hline 10.01 & 10.0 & 9.9 & -.1 & 24.72 & 25.0 & 25.1 & +.2 \\
\hline 10.09 & 10.0 & 10.0 & .0 & & & & \\
\hline
\end{tabular}

TABLE 1.-Determination of invert sugar

- The first 17 values under this heading were calculated by the equation $S=0.177+1.0124 I$, where $S=$ milligrams of invert sugar, and $I=$ milliliters of $0.0323 \mathrm{~N}$ iodine consumed.

b The last 28 values under this heading were calculated by the equation $S=0.817+0.855 I+0.005117 I^{2}$, where $S=$ milligrams of invert sugar, and $I=$ milliliters of $0.0323 \mathrm{~N}$ iodine consumed. 
TABLE 2-Iodine-invert sugar equivalents

\begin{tabular}{|c|c|c|c|c|c|c|c|c|c|c|}
\hline \multirow{3}{*}{$\underset{\text { iodine }}{0.0323 N}$} & \multicolumn{10}{|c|}{ Fractional milliliters of $0.0323 \mathrm{~N}$ iouine } \\
\hline & 0 & 0.1 & 0.2 & 0.3 & 0.4 & 0.5 & 0.6 & 0.7 & 0.8 & 0.9 \\
\hline & \multicolumn{10}{|c|}{ Milligrams of invert sugar } \\
\hline$m l$ & & & & & & & & & & \\
\hline 0 & (n) & $-\ldots$ & . n & 0.48 & 0.58 & 0.68 & 0.78 & 0.89 & 0.99 & 1. 09 \\
\hline 1 & 1.19 & 1. 29 & 1. 39 & 1. 49 & 1. 59 & 1. 70 & 1.80 & 1.90 & 2. 00 & 2. 10 \\
\hline 2 & 2.20 & 2. 30 & 2.40 & 2.51 & 2. 61 & 2. 71 & 2.81 & 2. 91 & 3. 01 & 3.11 \\
\hline 3 & 3. 21 & 3. 31 & 3.41 & 3. 52 & 3. 62 & 3. 72 & 3. 82 & 3. 92 & 4. 02 & 4. 12 \\
\hline 4 & 4. 23 & 4. 33 & 4.43 & 4. 53 & 4. 63 & 4. 73 & 4. 83 & 4. 94 & 5. 04 & 5.14 \\
\hline 5 & 5. 24 & 5. 33 & 5.41 & 5. 50 & 5. 59 & 5.67 & 5. 77 & 5. 86 & 5. 95 & 6. 04 \\
\hline 6 & 6.13 & 6. 22 & 6.32 & 6.41 & 6.50 & 6.59 & 6.68 & 6. 78 & 6.87 & 6. 96 \\
\hline 7 & 7.05 & 7.15 & 7. 24 & 7. 33 & 7.43 & 7. 52 & 7. 61 & 7. 70 & 7. 80 & 7.89 \\
\hline 8 & 7. 98 & 8.08 & 8.17 & 8. 27 & 8.36 & 8.45 & 8.55 & 8.64 & 8. 74 & 8.83 \\
\hline 9 & 8.93 & 9.02 & 9.12 & 9.21 & 9.31 & 9.40 & 9.50 & 9. 59 & 9. 69 & 9. 79 \\
\hline 10 & 9.88 & 9.98 & 10.07 & 10.17 & 10.26 & 10.36 & 10.45 & 10.55 & 10.65 & 10. 74 \\
\hline 11 & 10.84 & 10.94 & 11.03 & 11.13 & 11.23 & 11. 33 & 11.42 & 11. 52 & 11. 62 & 11. 71 \\
\hline 12 & 11. 81 & 11. 91 & 12.01 & 12.11 & 12.21 & 12.30 & 12.40 & 12.50 & 12.60 & 12. 70 \\
\hline 13 & 12.80 & 12.90 & 12. 99 & 13.09 & 13.19 & 13. 29 & 13. 39 & 13.49 & 13. 59 & 13. 69 \\
\hline 14 & 13. 79 & 13.89 & 13.99 & 14. 09 & 14.19 & 14. 29 & 14. 39 & 14.49 & 14. 59 & 14. 69 \\
\hline 15 & 14. 79 & 14.89 & 14.99 & 15.10 & 15.20 & 15. 30 & 15.40 & 15.50 & 15.60 & 15. 71 \\
\hline 16 & 15.81 & 15.91 & 16. 01 & 16.11 & 16. 21 & 16. 32 & 16.42 & 16. 52 & 16.63 & 16. 73 \\
\hline 17 & 16.83 & 16. 93 & 17.04 & 17.14 & 17.24 & 17. 35 & 17.45 & 17.55 & 17. 66 & 17. 76 \\
\hline 18 & 17.86 & 17. 97 & 18.07 & 18. 18 & 18.28 & 18. 39 & 18.49 & 18.60 & 18. 70 & 18.81 \\
\hline 19 & 18.91 & 19.01 & 19.12 & 19. 22 & 19. 33 & 19.44 & 19.54 & 19.65 & 19. 75 & 19.86 \\
\hline 20 & 19. 96 & 20.07 & 20.18 & 20.28 & 20.39 & 20.49 & 20.60 & 20.71 & 20.81 & 20.92 \\
\hline 21 & 21.03 & 21.14 & 21.24 & 21. 35 & 21.46 & 21. 56 & 21.67 & 21. 78 & 21.89 & 22.00 \\
\hline 22 & 22.10 & 22.21 & 22.32 & 22.43 & 22.54 & 22.64 & 22.75 & 22.86 & 22.97 & 23.08 \\
\hline 23 & 23. 19 & 23.30 & 23.41 & 23.52 & 23.62 & 23.73 & 23.84 & 23.96 & 24.07 & 24.18 \\
\hline 24 & 24.28 & 24. 39 & 24.50 & 24.61 & 24.72 & 24.83 & 24.95 & 25. 06 & 25.17 & 25.28 \\
\hline
\end{tabular}

\section{Effect of Sucrose on the Reducing Power of Invert Sugar}

It has been shown by many investigators that sucrose, even after careful purification, has a reducing effect on alkaline copper solutions. Thus, in using any method employing these reagents, the question arises whether to make a correction for the reduction of pure sucrose or to express the results on the basis of invert sugar alone. If a correction is to be made, the reducing power of very pure sucrose must be determined. Bates and Jackson [5], using Soldaini's reagent (a copper carbonate-bicarbonate solution), found a reduction of copper corresponding to 0.006 percent invert sugar content in pure sucrose. Kraisy, using a copper carbonate tartrate solution, found 0.007 percent, while Sandera and Merceo, and the New York Sugar Trade Laboratory, using the same method [6], found 0.003 percent as the invert content of sucrose. Ofner reports that $10 \mathrm{~g}$ of sucrose reduces copper equivalent to $1 \mathrm{ml}$ of
$0.0323 N$ iodine, or 0.01 percent invert sugar. Jackson and McDonald [2] found that $10 \mathrm{~g}$ of sucrose reduced copper equivalent to $1.1 \mathrm{ml}$ of $0.0323 N$ iodine but did not determine the pure invert sugar equivalent. In the present investigation it has been found that the reducing power of $10 \mathrm{~g}$ of a National Bureau of Standards Standard Sample of Sucrose is equivalent to $1.1 \mathrm{ml}$ of iodine, or 0.013 percent of invert sugar. ${ }^{2}$

If the sucrose hydrolyzes during the determination, it would be expected that methods employing different boiling times and solutions varying in $\mathrm{pH}$ would give varying results. It is known that the alkaline solutions, such as Soxhlet's, have a hydrolytic effect on sucrose, and for this reason they are not adaptable to the determination of

\footnotetext{
${ }^{2}$ Repeatedly recrystallized and freshly prepared sucrose samples occasionally gave values as low as 0.006 percent of invert sugar when analyzed by this method.
} 
refined sugars. A series of analyses was made in which $1 \mathrm{mg}$ of invert sugar and a sample of sucrose containing $1.3 \mathrm{mg}$ of apparent invert sugar was determined by the method under consideration, using 1 to 20 minutes of boiling time. The results are shown in figure 1. It is concluded from the difference in the slopes of the curves at the 5-

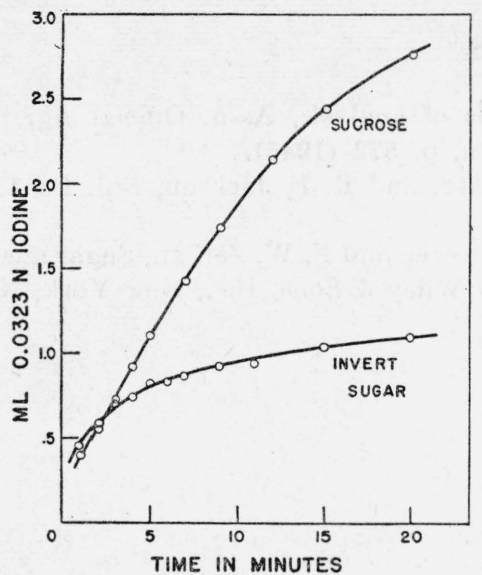

Figure 1.-Effect of the time of boiling on the determination of invert sugar and sucrose.

minute boiling time (the conditions specified in the method) that the reducing effect of sucrose is caused, at least in part, by substances formed during the analysis rather than those in the original sample. These results also show that when sucrose is present, small variations in the boiling time will have a greater effect on the amount of copper reduced than when invert sugar alone is present.

Many investigators, using different copper solutions under varying conditions, have studied the effect of sucrose on the reducing power of invert sugar. Ofner reported that, irrespective of the relative amounts of sucrose and invert sugar present, $10 \mathrm{~g}$ of the former or $1 \mathrm{mg}$ of the latter reduced copper equivalent to $1 \mathrm{ml}$ of $0.0323 \mathrm{~N}$ iodine.

In table 3 the results of the analyses of seven samples of sucrose, alone and with known amounts of added invert sugar, are tabulated. It was found that when the total invert sugar content of $10 \mathrm{~g}$ of sucrose was not more than about $5 \mathrm{mg}$, the effect of the sucrose and added invert sugar seemed to be additive. It is therefore recommended that for sucrose samples containing 0.05 percent or less of invert sugar the iodine used be converted to invert sugar by the use of table 2 . The results thus obtained may be reported as apparent invert sugar, or a correction amounting to $1.1 \mathrm{ml}$ of $0.0323 \mathrm{~N}$ iodine for each $10 \mathrm{-g}$ sample of sucrose may be subtracted in order to compensate for the reduction of pure sucrose. In the latter case the results would be expressed as invert sugar and would not include the apparent invert sugar caused by the reducing action of the pure sucrose.

For amounts of invert sugar above $5 \mathrm{mg}$, the table published by Jackson and McDonald [2] is more convenient and accurate.

TABLE 3.-Reducing power of sucrose alone and with added invert sugar

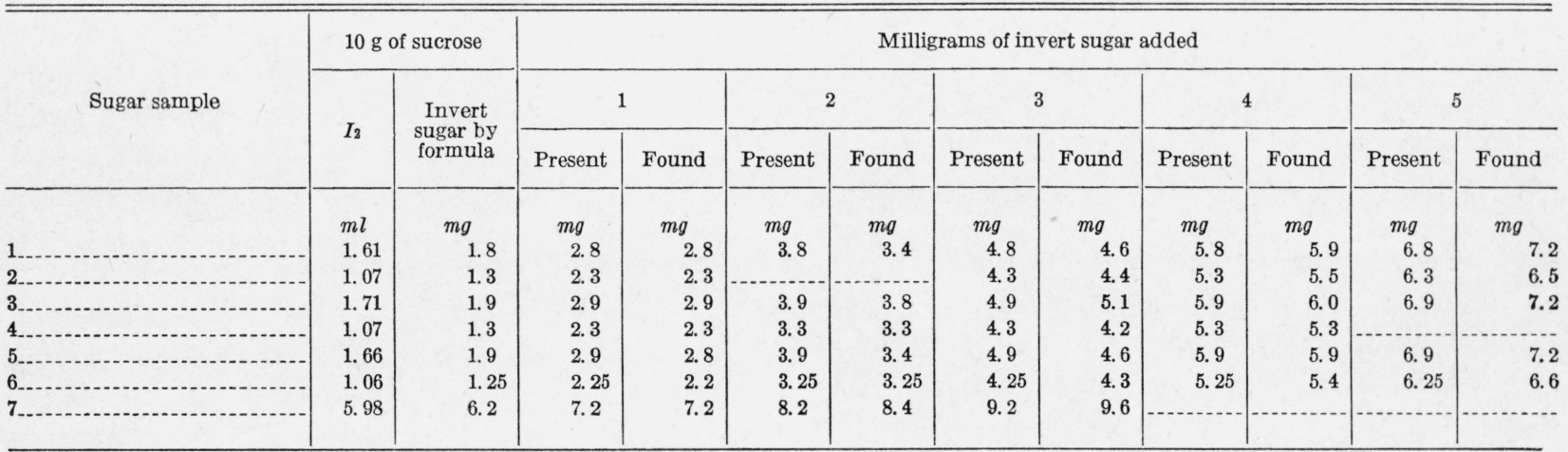




\section{Summary and Conclusions}

Ofner's method, as modified by Jackson and McDonald, has been used for the determination of invert sugar, and a table giving the invertsugar equivalents of the iodine consumed has been prepared. It has been shown that this is a convenient and reliable method for the analysis of high-grade refined sugars.

\section{References}

[1] R. Ofner, Z. Zuzkerind. Čechoslovak Rep. 53, 733 (1928-29); 56, 249 (1931-32); 59, 52 (1934-35).

[2] R. F. Jackson and E. J. McDonald, J. Assn. Official Agr. Chem. 26, 462 (1943).

[3] R. F. Jackson and E. J. McDonald, J. Assn. Official Agr. Chem. 24, 775 (1941).

Washington, August 30, 1946.
[4] Methods of analysis, Assn. Official Agr. Chem., 6th edition, p. 572 (1945).

[5] F. J. Bates and R. F. Jackson, Bul. BS 13, 67 (1916) S268.

[6] C. A. Browne and F. W. Zerban, Sugar analysis, p. 843 (John Wiley \& Sons, Inc., New York, N. Y., 1941). 